\title{
Assessment of hydrological stationarity of the Border Rivers catchment
}

\author{
$\underline{\text { A. K. Raut }}^{\text {a }}$, G. Kibria ${ }^{\text {a }}$, N. Nandakumar ${ }^{\text {a }}$ and S. Maheswaran ${ }^{\text {a }}$ \\ ${ }^{a}$ WaterNSW, Parramatta, NSW \\ Email: Ashok.Raut@waterNSW.com.au
}

\begin{abstract}
WaterNSW is currently developing the water resources planning models for all regulated NSW valleys including the Border Rivers Valley (BRV), where WaterNSW has responsibility for bulk water supply. The planning models will enable WaterNSW to assess the level of services and undertake the assessment of future water resources infrastructure options. The planning model requires long-term catchment inflows, which are available but for shorter durations. For this reason, the calibrated catchment rainfall-runoff model is used to calculate long-term inflows based on available long-term rainfall and evaporation data.
\end{abstract}

Recent studies and relevant data show that Border Rivers catchment has undergone the significant land use changes in the recent time, particularly, in the second half of the 20th Century. As a result, the runoff characteristics of the catchments are likely to change in these years. As the part of the model calibration, this paper investigates the hydrological stationarity of the catchments over the period ranging from 1970 to date, where the observed flow data are available for selected catchments. For this study, four unregulated catchments have been considered with insignificant abstraction. The daily Sacramento rainfall-runoff model was developed for each catchment.

To assess the catchment stationarity, the simulation period has arbitrarily been divided into two parts: pre1992 (1975 to 1991) and post-1992 (1992 to 2016). The catchment rainfall-runoff models are calibrated over the pre-1992 period and validated against the post-1992 flow data and vice-versa. The simulation results clearly show that the catchment runoff characteristics have changed over the time. The runoff has, in general, decreased over the catchment in recent years, and the decrease in runoff appears to be significant and consistent across the catchment. The whole exercise was repeated with catchment rainfall and Morton Wet Environment Evaporation data from SILO database. The results still hold. Since it has been assumed that the rainfall and potential evaporation data used for rainfall-runoff simulation are stationary, the authors believe that the potential reasons for the non-stationarity in the runoff are the following but not limited to:

- Changes in land use in the catchment in recent time,

- Increases in the on-farm storage in the catchment, and

- Increases in the unregulated abstraction in the catchment in the recent time.

More detailed works will be required to ascertain the cause for catchment non-stationarity with greater confidence. Based on the outcomes of this analysis, WaterNSW has used the recent (post-1992) data for the calibration of the rainfall-runoff model for the Border Rivers to estimate the catchment inflows, which have been used for the development of the planning model.

Keywords: Border Rivers, rainfall-runoff, non-stationarity, calibration, validation 


\section{INTRODUCTION}

WaterNSW is currently developing the water resources planning models for all regulated NSW valleys including the Border Rivers Valley (BRV), where WaterNSW has responsibility for bulk water supply. The planning models will enable WaterNSW to assess the level of services and undertake the investigations of future water resources infrastructure development and management options. A water resources planning model is a water balance model, which quantifies the movement of water within the system under natural and man-made conditions and relevant water sharing rules. Thus, the model development involves (i) the estimation of catchment inflows under natural conditions driven by climatic variables, and (ii) the determination of flows under various demand conditions and defined water sharing rules taking the system and infrastructure constraints into consideration. The natural catchment inflow input in the model is, often, estimated using Rainfall-Runoff model using observed hydro-climatic data. For the confident use of a rainfall-runoff model, it requires to be calibrated and validated using good quality observed catchment rainfall, potential evaporation and stream flow data.

Often, such option analyses require the stream flow records of much longer periods than the ones for which the observed stream flows are available. Also, as the period of analyses gets longer, it is likely that the catchments undergo the significant land use and other physical changes over the simulation period, affecting the catchment runoff characteristics. This paper investigates the hydrological stationarity of the catchment over the period ranging from 1975 to 2016 for which the stream flow records are available for simulation.

\section{STUDY AREA OVERVIEW}

The Border Rivers catchment is located at the western side of the Great Dividing Range. The upper part of the entire catchment to the east is in the Great Dividing Range and has steep topography and high relief. This grades into undulating hills, and gradually flattens towards the West around Boggabilla (Figure 1). The elevation ranges around $1500 \mathrm{~m}$ in the East in the Great Dividing Range to $150 \mathrm{~m}$ in the West around Mungindi. It has a total area of about 48,600 sq km and lies, in approximately equal sections, in Northern NSW and Southern QLD. The principal streams of the valley are the Macintyre and Severn Rivers in the South-East, the Dumaresq River in the East and Macintyre Brook and the Weir River in the North and NorthWest. With the exemption of the Weir River, each of these main rivers is regulated with a major dam located upstream of each catchment.

The monthly rainfall pattern over the catchment is almost unimodal with the summer months having most rainfall (Figure 2). The Bureau of Meteorology gridded daily rainfall and potential evapotranspiration data from 1970 to 2016 have been used for the analyses. The monthly potential evaporation pattern over the catchment is like rainfall pattern, with summer months having higher potential evaporation (Figure 3). The stream flow discharge is measured along the river reaches at more than 70 existing telemetered gauging sites by the responsible agencies in NSW and Queensland. These data can be found at the NSW Hydstra site or the WaterNSW water portal (https://realtimedata.waternsw.com.au/water.stm) and QLD Government Department of Natural Resources Water Monitoring Information Portal (https://watermonitoring.information.qld.gov.au).

The agriculture practice in the valley has been dominated by cotton crop in the recent years (Figure 4). According to the recent statistics, the population of the Border Rivers Valley is about 50,000. The population centers are scattered over the catchment (Figure 5). Some of major population centers in the catchment are Inverell, Goondiwindi, Stanthorpe, Glen Innes and Tenterfield. Figure 1 clearly shows that some of these population centers are located either within or adjacent to the selected catchments, where agriculture activities are expected involving potential landuse changes over the recent years.

For this study, four unregulated headwater catchments have been considered with insignificant abstraction. The outlets of the catchments are identified by respective gauging locations (\#416008, \#416016, \#416032, and \#416039) as shown in Figure 1. These are major headwater tributaries in the Border Rivers system with relatively longer observed flow records. The details of these tributary catchments are given in Table $\mathbf{1}$.

\section{RAINFALL-RUNOFF MODEL}

WaterNSW has used the daily Sacramento rainfall-runoff hydrological model for the estimation of the natural catchment inflows (Burnash et al, 1973). There are several major tributaries in the Border Rivers (Figure 1). 
As the part of the broader task of development of water resources planning model for the Border Rivers, the detailed rainfall-runoff simulation of all tributaries has been carried out to estimate the catchment flows.

As it can be seen from Table 1, the streamflow record length varies for these catchments and a common period 1975 to 2016 was selected for the model calibration and validation. This period has arbitrarily been divided into two parts: pre-1992 (1975 to 1991) and post-1992 (1992 to 2016). The catchment rainfall-runoff models are calibrated using the post-1992 data and validated using the pre-1992 data and vice-versa using AWAP gridded rainfall and Penman potential evaporation data. Optimisation function used is SCE then Rosenbrook. Objective function used is Square-root daily, exceedance and bias. The goodness-of-fit of the model calibrations and validations has been measured using the goodness-of-fit statistics commonly used in the water modelling industry such as coefficient of correlation, daily NSE, monthly NSE, mean flow, daily flow volume bias, cumulative flow volume bias and the comparison plots of flow time series, cumulative volumes, flow duration curves. To maintain the brevity of the paper, these statistics have not been given here.

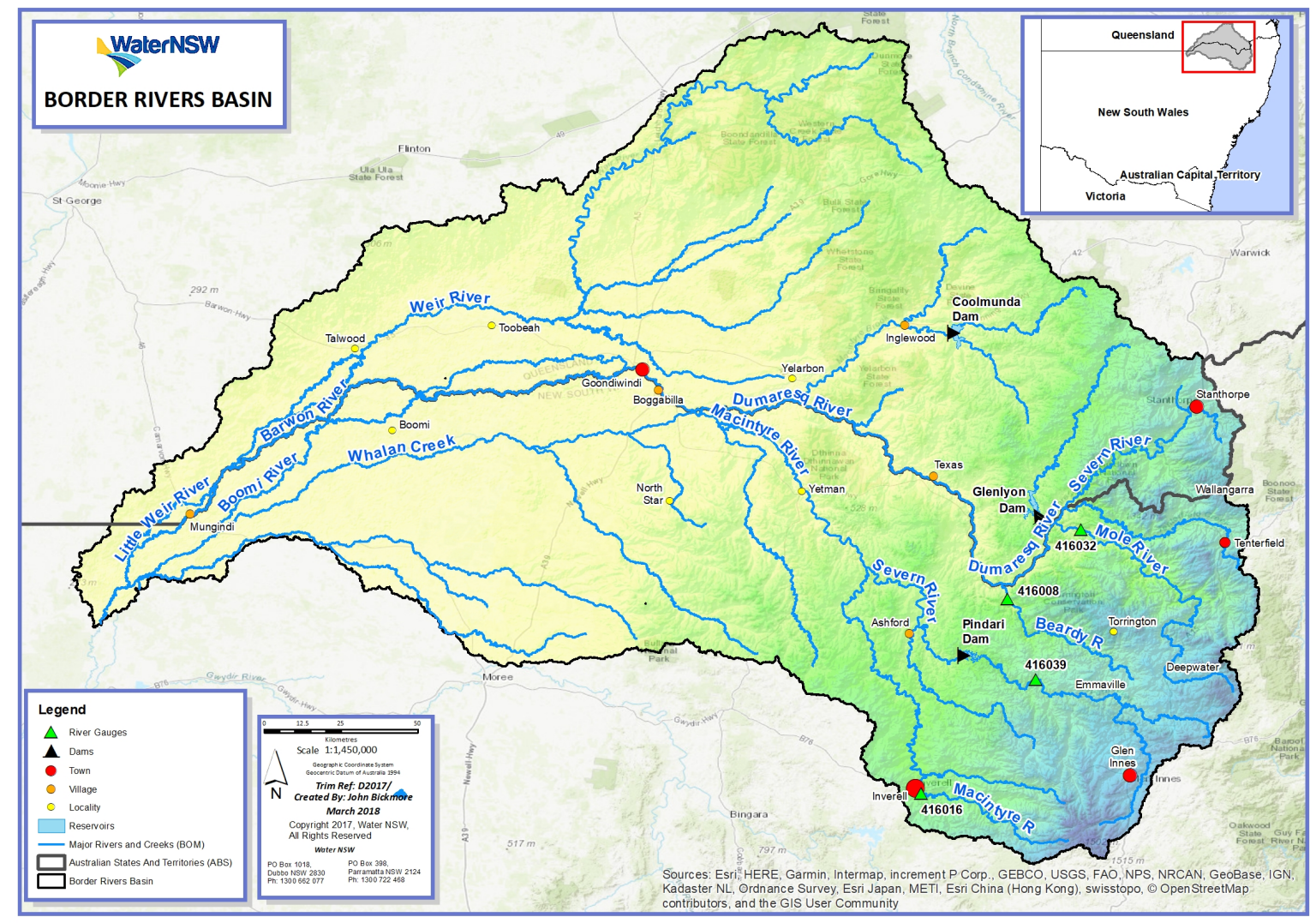

Figure 1. Border Rivers catchment.

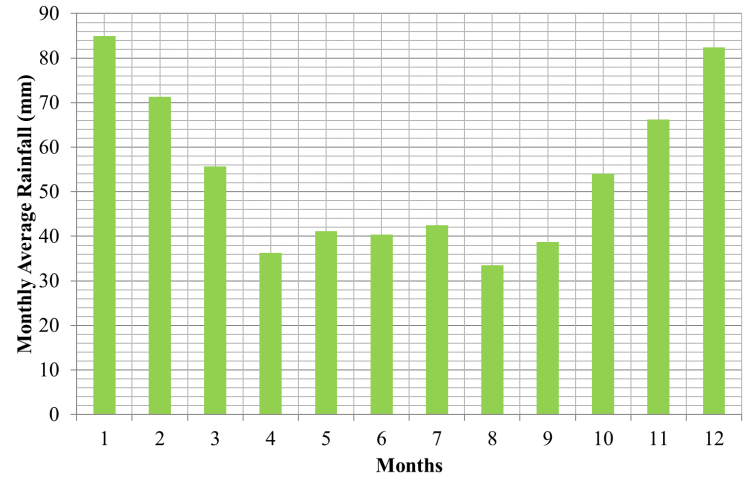

Figure 2. Monthly rainfall pattern over the catchment.

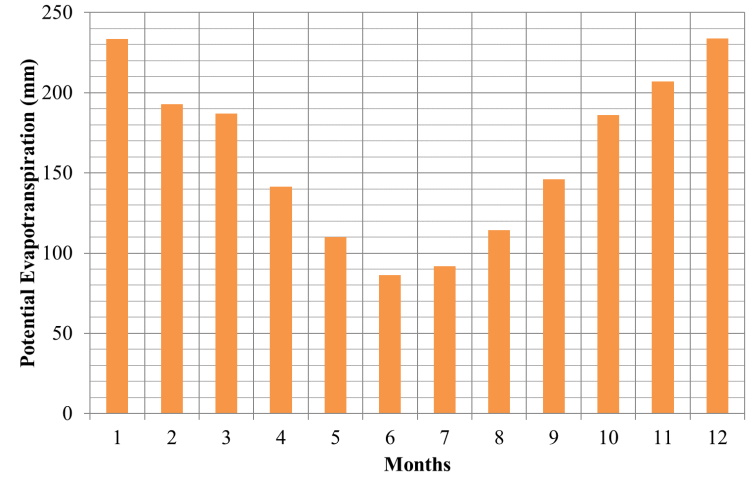

Figure 3. Monthly Penman potential evapotranspiration pattern over the catchment. 


\subsection{Catchment Delineation}

The 1-second (30 m) SRTM Derived Hydrological Digital Elevation Model (DEM-H) Version 1.0 has been used to delineate the catchment areas for the selected gauging locations. The catchment areas have been verified against the areas of the gauging locations as reported in the NSW and QLD water portals.

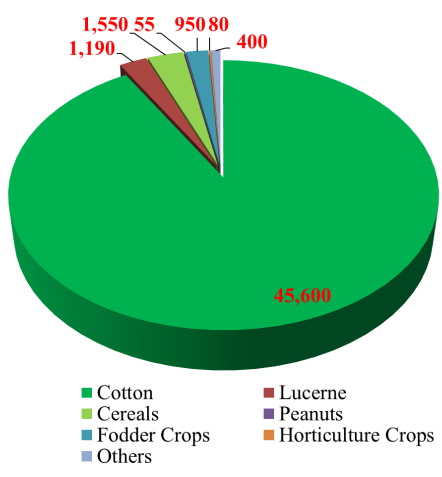

Figure 4. Recent agriculture practice in the catchment (Data Source: Border Rivers Commission).

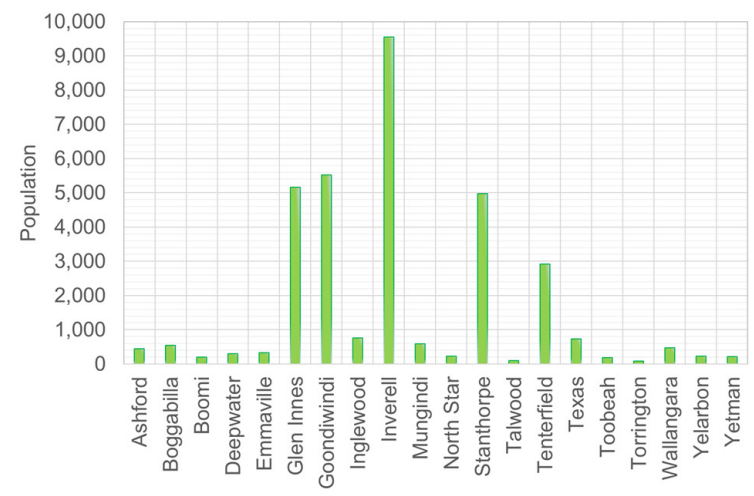

Figure 5. Population in the catchment (Data Source: Australian Bureau of Statistics, 2016).

Table 1. Details of the catchments

\begin{tabular}{|l|l|l|r|l|}
\hline Tributary & Gauging Station & Gauging Location & Catchment Area (sq km) & Data Available Period \\
\hline Beardy River & 416008 & Haystack & 866 & 1970 to date \\
\hline Macintyre River & 416016 & Inverell & 726 & 1971 to date \\
\hline Mole River & 416032 & Donaldson & 1,591 & 1969 to date \\
\hline Severn River & 416039 & Strathbogie & 1,745 & 1974 to date \\
\hline
\end{tabular}

\subsection{Modelling Software}

WaterNSW is currently using the eWater Source modelling software (Source Online Documentation) for the development of daily water resources planning models for all NSW Valleys. A simple daily Source model has been developed for each catchment. The Sacramento hydrological model in-built in the Source has been used for the simulation.

\subsection{Model Simulation Results}

The simulation results for gauging station, 416016, has been discussed here in greater details to illustrate the process. The model calibration was firstly carried out using post-1992 flow data with warming period from 1985 and then validated against pre-1992 flow data and vice versa. The model calibration and validation diagnostic plots are shown in Figure 6 to Figure 11. For pre-1992 validations, the pre-1992 calibration and post-1992 validation, only the cumulative flow volume plots have been shown here. Also, only cumulative flow volume graphs have been shown for all model validations to maintain the brevity of the paper. NashSutcliffe Efficiency (NSE) values for calibrations vary from 0.5 to 0.9. The volume bias in the pre-1992 calibration (Figure 8), particularly during the Millennium Drought period, has been discussed in detail in Raut et al. (2018). The simulation results show that the calibration based on the post-1992 data underestimates the flow in the pre-1992 period and vice versa.

\subsection{Consolidated Simulation Results}

In the similar manner, the calibrations and validations for the remaining three catchments have been carried out. The cumulative flow plots for all four catchments have been shown in Figure 12 and Figure 13 for pre1992 and post-1992 validations respectively. The first plot presents the flow validation results for pre-1992 period based on post-1992 calibrations. The second plot presents the reverse. It is evident from the simulation 
results that the calibrations based on the post-1992 flow data significantly underestimate the flow in the pre1992 period and vice versa across the catchment.

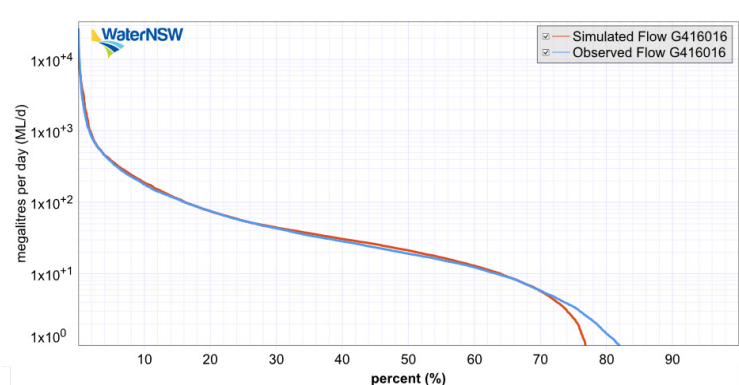

Figure 6. Flow duration for post-1992 calibration.

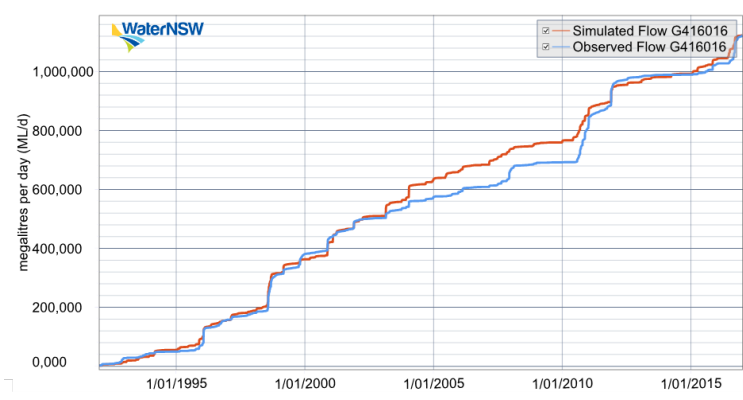

Figure 8. Cumulative flow volume for post-1992 calibration.

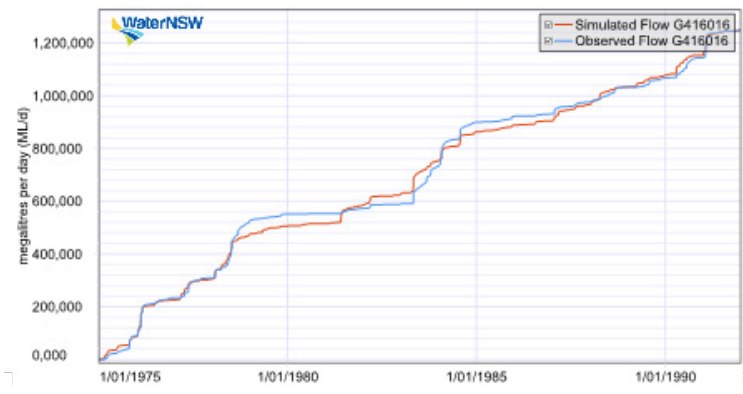

Figure 10. Cumulative flow volume for pre-1992 calibration.

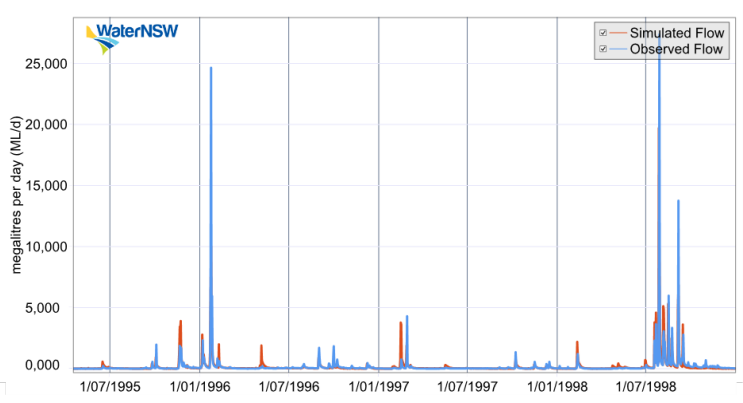

Figure 7. Flow time-series for post-1992 calibration.

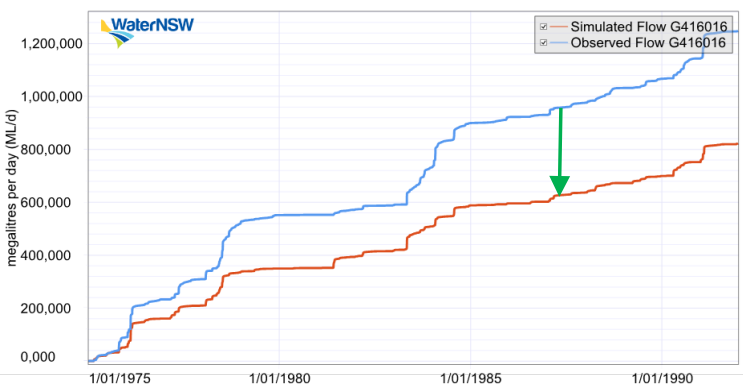

Figure 9. Cumulative flow volume for pre-1992 validation.

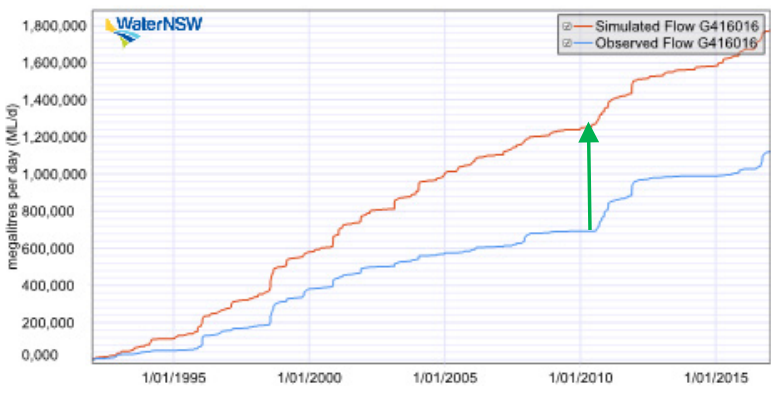

Figure 11. Cumulative flow volume for post-1992 validation.

The consistent differences between the observed and simulated flows in the validation periods could be due to error in in the climatic data used or nonstationary observed flows. To eliminate the first reason, the whole exercise was repeated with catchment rainfalls and Morton Wet Environment Evaporation data from SILO database (https://www.longpaddock.qld.gov.au/silo/ point-data/). For this, the stations that have data available in the SILO database and are located within $20 \mathrm{~km}$ outside the catchment boundary were firstly identified. The Thiessen polygon method was applied to obtain the catchment rainfalls. Rainfall data from 9,12,10 and 21 stations were used to calculate the areal rainfalls for catchments: 416008, 416016, 416032 and 416039 respectively. For potential evaporation, Morton Wet Environment Evaporation data was used since Penman PET is not available in SILO database. This exercise also resulted in under-estimation of flows for pre-1992 validation and the over-estimation of flows for the post-1992 validation period, consistent with the results from the simulation using the AWAP gridded data. 


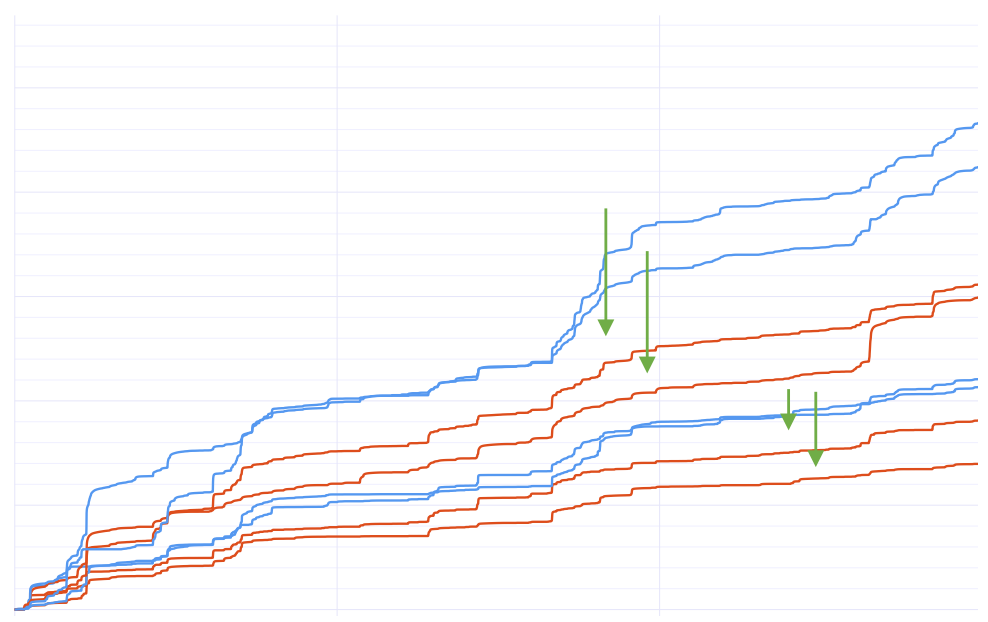

Figure 12. Pre-1992 validation results.

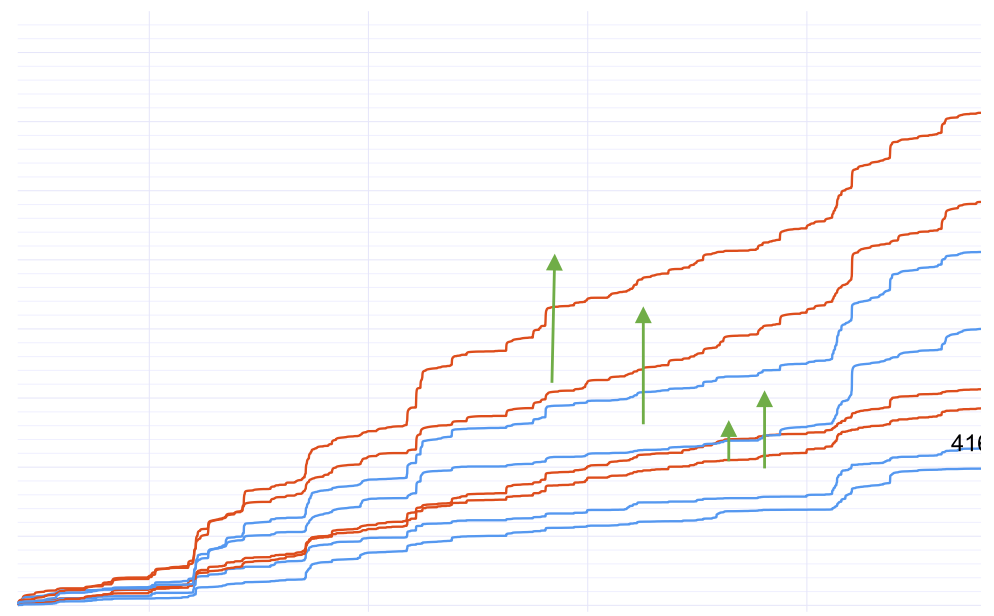

Figure 13. Post-1992 validation results.

\section{DISCUSSIONS AND CONCLUSIONS}

The cumulative volume bias values of the calibration and validation simulations of all four catchments are given in Table 2. The results clearly show that the catchment runoff characteristics have changed over the time. The runoff has, in general, decreased over the catchment in the recent time, and the decrease in runoff appears to be consistent and significant across the catchment. Some of the potential reasons for this trend in catchment runoff may be attributed to:

- Change in land use and landcover

- Increase in the on-farm dams in the catchment, and

- Increase in the unregulated abstraction.

The native vegetation has been cleared in the recent time for agriculture (DSITI, 2015). This is also evident from Figure 14, where the crop area has gradually increased until the Millennium Drought. The decrease in area after the drought may be more attributed to the water scarcity during recent droughts. In the similar manner, Figure 15 shows the increase in the on-farm storages in the catchment in the recent years. Also, it is expected that during recent droughts, the unregulated abstractions in the catchment may have increased. These landuse and on-farm storage observations are prevailing more outside the catchment areas selected for this study. Nevertheless, it is evident that there are significant human activities in the selected catchments that warrant similar observations. All these attributes responsible for the change in runoff characteristics need to be further investigated in greater details. Nevertheless, based on this outcome, WaterNSW has used the post- 
1992 data for the calibration of the model for the Border Rivers. This is mainly because the calibration based on recent data is expected to be more representative of the catchment behaviour in the recent years and in near future.

Table 2. Cumulative volume bias (\%) of the calibration and validation simulations

\begin{tabular}{|l|r|r|r|r|}
\hline Catchment & Post-1992 Calibration & Pre-1992 Validation & Pre-1992 Calibration & Post-1992 Validation \\
\hline C416008 & 0.78 & -18.59 & -2.58 & 27.80 \\
\hline C416016 & 0.05 & -33.69 & -0.83 & 67.74 \\
\hline C416032 & 0.29 & -22.07 & -0.43 & 49.14 \\
\hline C416039 & 3.76 & -28.71 & 4.11 & 45.84 \\
\hline
\end{tabular}

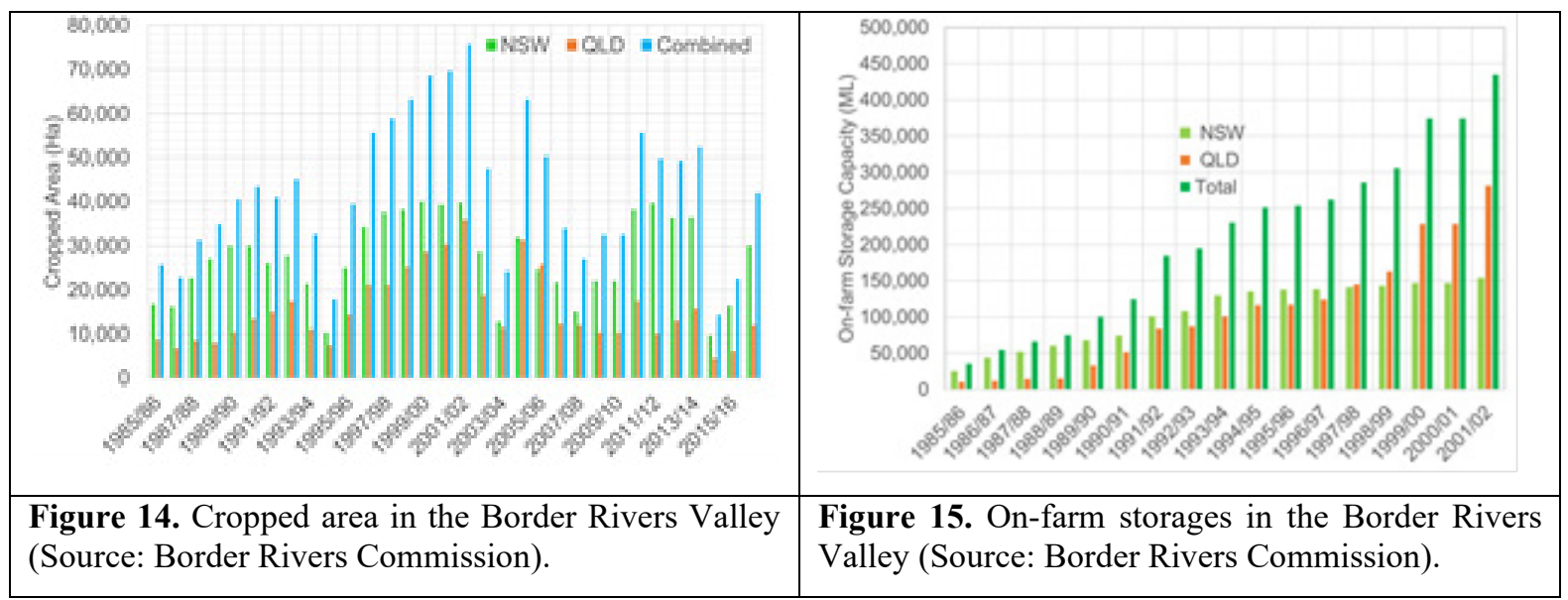

\section{ACKNOWLEDGEMENTS}

The authors express their sincere gratitude to Applied Hydrology Team Leader Mr. Robert Craig, Water Modelling Team Leader Mr. Jason Martin, and acknowledge the assistance provided by the Supply Modelling teammates during the development of the Border Rivers planning model.

\section{REFERENCES}

Burnash, R.J.C, Ferral, R.L. \& McGuire, R.A. (1973) A generalized streamflow simulation system: conceptual modeling for digital computers, Technical Report, Joint Federal and State River Forecast Center, US National Weather Service and California Department of Water Resources, Sacramento, CA.

Department of Science, Information Technology and Innovation (DSITI), 2015. Land use summary 19992013 for the Border Rivers and Moonie catchments, Government of Queensland, Australia, June 2015.

Lutton, S., Sheldon, F. and Bunn, S.E., 2010. Morphological characteristics of on-farm water storages and their similarity to natural waterbodies in the Border Rivers Catchment, Australia. Aquatic Conservation, Marine and Freshwater Research 20:47-57 DOI:10.1002/aqc.1072.

Nandakumar, N., Raut A., Singh G. and Maheswaran, S, 2018. Investigation of the Use of Australian Water Availability Project Rainfall Data for the Development of eWater Source Models for Water Planning in NSW.Hydrology and Water Resources Symposium, Melbourne, Australia, 3-6 December 2018.

Raut A. K., Nandakumar, N. and Kibria, G., 2018. Calibration of Sacramento Model for a catchment with unknown abstraction. Hydrology and Water Resources Symposium, Melbourne, Australia, 3-6 December 2018.

Source Documentation online, https://ewater.atlassian.net/wiki/display/SD41/Basic+Concepts 